\title{
Acute appendicitis due to Cytomegalovirus in an apparently immunocompetent patient: a case report
}

\author{
Maria Bruna Pasticci ${ }^{1 *}$, Simona Corsi ${ }^{2}$, Francesca Spigarelli ${ }^{2}$, Stefano Correnti ${ }^{5}$, Daniela Francisci ${ }^{1}$, \\ Roberto Castronari ${ }^{3}$, Pamela Baldin ${ }^{6}$, Annapaola Prosperini ${ }^{4}$, Franco Baldelli ${ }^{1}$, Elio Cenci ${ }^{3}$, Alessandra Sensini ${ }^{3}$ \\ and Olivia Morelli ${ }^{2}$
}

\begin{abstract}
Introduction: In healthy subjects, Cytomegalovirus infection can be asymptomatic or manifest as mononucleosis syndrome, but organ disease has also been reported. However, in immunocompromised patients this infection can lead to its most significant and severe disease and even mortality. When Cytomegalovirus causes a gastrointestinal tract infection, it more commonly manifests with luminal tract disease and is usually characterized by ulcerative lesions. Appendicitis is a rare manifestation, and has been reported mainly in human immunodeficiency virus-infected patients or patients with other causes of immunocompromise.

Case presentation: The authors report on a case of acute primary Cytomegalovirus infection complicated with acute appendicitis due to Cytomegalovirus in an apparently immunocompetent 24-year-old Caucasian man also suffering from primary sclerosing cholangitis and ulcerative colitis. Diagnosis was based on clinical manifestations, serology results, as well as microbiological and histological findings. Treatment consisted of surgery and anti-Cytomegalovirus therapy.

Conclusions: Cytomegalovirus should be included among the etiologic agents of acute appendicitis in patients with primary sclerosing cholangitis and ulcerative colitis. Currently, there are no definitive data regarding the frequency of Cytomegalovirus appendicitis and the role of anti-Cytomegalovirus treatment in human immunodeficiency virus-negative and apparently immunocompetent subjects.
\end{abstract}

Keywords: Cytomegalovirus appendicitis, Primary Cytomegalovirus infection, Primary sclerosing cholangitis, Ulcerative colitis

\section{Introduction}

In healthy subjects, Cytomegalovirus (CMV) infection can be asymptomatic or manifest as mononucleosis syndrome, but organ disease has also been observed [1-3]. However, in immunocompromised patients, CMV infection can lead to its most significant and severe disease manifestations. In bone marrow recipients, CMV pneumonia is the most common life-threatening infection after transplantation [1]. CMV infection is the most common viral infection in patients with human immunodeficiency virus (HIV) infection and CMV retinitis

\footnotetext{
* Correspondence: mariabruna.pasticci@unipg.it

'Infectious Disease, Department Experimental Medicine and Biochemical

Sciences, University of Perugia, 06100 Perugia, Italy

Full list of author information is available at the end of the article
}

continues to be the most frequent sight-threatening infection in the era of highly active antiviral therapy [1]. In patients with HIV infection, CMV disease of the gastrointestinal tract is also frequently observed [1,2]. CMV infection of the gastrointestinal tract can occur anywhere in the gastrointestinal system but luminal tract disease is the most common localization and is usually characterized by ulcerative lesions. Esophagitis and colitis are the most frequent manifestations; however, CMV gastritis, small bowel enteritis, intestinal stricture, proctitis, cholangitis, hepatitis and pancreatitis have been observed [1-3]. CMV appendicitis is a rare manifestation, reported mainly in HIV infected patients [4,5]. Less frequently involved are patients with other causes of immunocompromise [6-8] and very few cases have been 
reported in apparently immunocompetent subjects [9-12]. However, Dzabic et al. have evidenced cells which were double positive for both early CMV antigens and interleukin (IL)-6 and/or IL- 8 in $63 \%$ of patients with confirmed acute appendicitis and have found a possible correlation with CMV infection and the severity of disease [11]. CMV was also the most frequently detected virus in a study including 38 children who had undergone appendectomy for acute appendicitis [12].

The authors report a case of acute primary Cytomegalovirus infection complicated with acute appendicitis due to Cytomegalovirus in an apparently immunocompetent patient also suffering from primary sclerosing cholangitis (PSC) and ulcerative colitis (UC).

\section{Case presentation}

A 24-year-old Caucasian man with fever and upper quadrant abdominal pain over the previous 20 days was admitted to our hospital. Before admission, ciprofloxacin and metronidazole, followed by cefixime had been prescribed. Six years prior, the patient had been diagnosed with PSC, UC, suspected retroperitoneal fibrosis, bile sludge and splenomegaly. For this, he was prescribed ursodiol 300mg BID and mesalamine $4 \mathrm{~g}$ per day. At that time, investigations included exploratory laparotomy and a biopsy of the perihepatic, retroperitoneal tissue which excluded malignancy. Over this six-year period, the patient presented with recurrent episodes of cholangitis, the serum level of aminotransferases remained substantially normal while there was a progressive worsening of cholestatic test results and a progressive liver enlargement along with fibrosis. Specifically, gamma glutamyl transpeptidase (GGT) and alkaline phosphatase (ALP) increased from $141 \mathrm{UI} / \mathrm{L}$ to $344 \mathrm{UI} / \mathrm{L}$ and $847 \mathrm{UI} / \mathrm{L}$ to 2534UI/L, respectively. Hepatic tissue stiffness, measured by FibroScan ${ }^{\oplus}$, progressed from 12.6 to $17.3 \mathrm{kPa}$.
The patient was never treated with immunosuppressive therapy or corticosteroids. One month before admission, an upper endoscopy was performed which excluded esophageal varices. One week before admission, a magnetic resonance of his abdomen and bile ducts revealed further enlargement of the liver, spleen and the tissue surrounding his hepatic hilum (Figure 1a), posterior to the pancreas head. The latter caused a compression of his second duodenal tract and a wrapping of the splenic and hepatic arteries. Beading and narrowing of the intrahepatic and common bile ducts (Figure 1b) resulted in more extension and a narrowing of the pancreatic duct was also reported.

At admission, our patient had a fever of $38.8^{\circ} \mathrm{C}$ and physical examination revealed tenderness of his epigastrium and right upper hypochondrium. Results from blood tests are reported in Table 1. Microbiological blood and urine investigations were negative for bacteria. A chest radiograph was normal while an abdominal sonography revealed an enlarged liver, thickened choledocus, dilatation of the intra-hepatic biliary tree, splenomegaly and lymphadenopathy of the hepatic hilus. A colonoscopy showed erythema of the colonic mucosa from the rectum to the cecum, with areas of increased erythema and telangiectasia in the ascending colon. Random biopsy showed focal atrophy of the colonic mucosa with edema and chronic inflammatory infiltrates, but specific investigations for CMV were not carried out. Imipenem 500mg IV four times daily was administered. Three days later, due to our patient's persisting fever and abdominal pain, imipenem was substituted with tigecycline 50mg IV BID. Further blood and urine cultures for bacteria were negative. Both the erythrocyte sedimentation rate (ESR) and C-reactive protein level (C-RP) remained high, whereas the white blood cell (WBC) and neutrophil counts decreased (Table 1) and the procalcitonin level
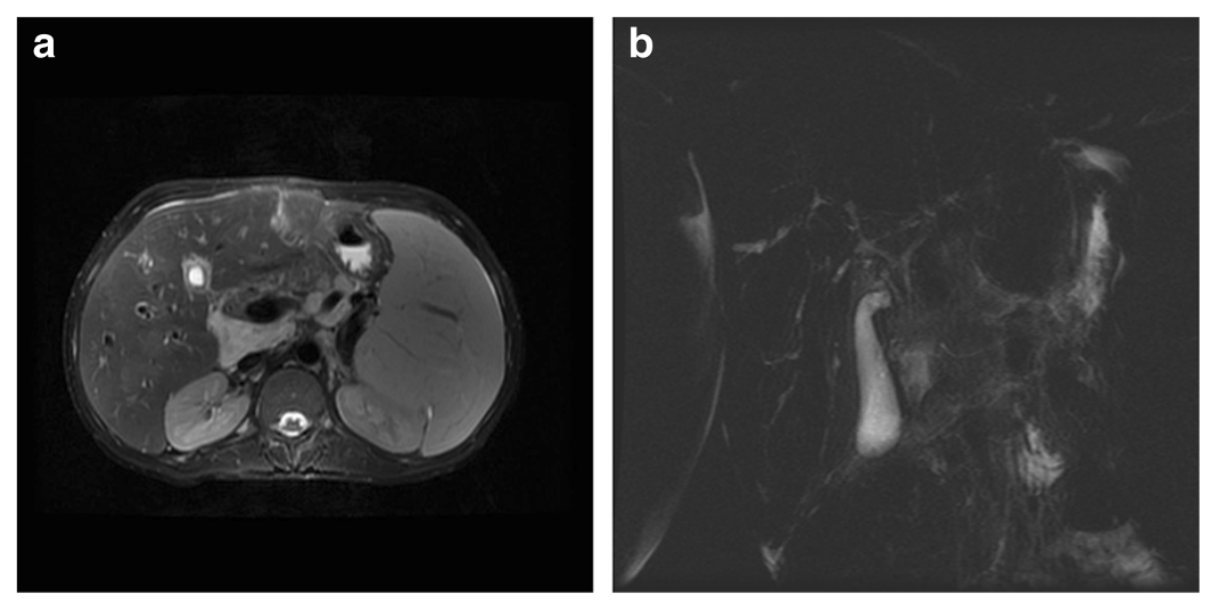

Figure 1 Magnetic resonance showing bile duct irregularities (a); T2-weighted image, depicting hepatic hilum tissue with contrast enhancement (b). 
Table 1 Laboratory tests

\begin{tabular}{|c|c|c|c|c|c|c|}
\hline & $2 / 22 / 2012$ & $3 / 3 / 2012$ & $3 / 6 / 2012$ & $3 / 7 / 2012$ & $3 / 19 / 2012$ & $04 / 11 / 2012$ \\
\hline$\overline{\text { WBCs }\left(3.60 \text { to } 9.60 \times 10^{3} \mu \mathrm{L}\right)}$ & 14.45 & 8.19 & 9.02 & 8.6 & 9.43 & 8.7 \\
\hline Neutrophils (42.0 to $75.0 \%)$ & 80.9 & 34.0 & 38.0 & 48 & 62 & 69.3 \\
\hline Lymphocytes (20.5 to $51.1 \%$ ) & 11.7 & 57.0 & 52.8 & 43 & 30 & 19 \\
\hline Monocytes (1.0 to $10.0 \%)$ & 6.6 & 5.0 & 5.3 & 8 & 6 & 9 \\
\hline Eosinophils ( $\leq 5 \%)$ & 0.5 & 0.0 & 0.7 & 0 & 2 & 2.2 \\
\hline Basophils ( $\leq 1 \%)$ & 0.3 & 3.0 & 3.2 & 1 & 0 & 0.5 \\
\hline $\mathrm{CD} 4+\mathrm{T}\left(430\right.$ to $1590 \mathrm{~mm}^{3}, 30$ to $\left.70 \%\right)$ & & & $1055(20.3 \%)$ & & $1132(41 \%)$ & \\
\hline $\mathrm{CD} 8+\mathrm{T}\left(220\right.$ to $1040 \mathrm{~mm}^{3}, 13$ to $\left.40 \%\right)$ & & & $3193(67 \%)$ & & $849(31 \%)$ & \\
\hline $\mathrm{Hb}(13.0$ to $17.0 \mathrm{~g} / \mathrm{dL})$ & 12.3 & 10.9 & 9.9 & 9.9 & 10.2 & 10.5 \\
\hline RBCs (4.30 to $5.80 \times 10^{6} \mu \mathrm{L}$ ) & 4.26 & 3.93 & 3.54 & 3.58 & 3.55 & 3.74 \\
\hline I.N.R (0.80 to 1.2$)$ & 1.40 & & & & 1.4 & 1.2 \\
\hline $\operatorname{PLT}(140$ to $440 \times 103 \mu \mathrm{L})$ & 374 & 215 & & & 383 & 355 \\
\hline Albumin ( 3.5 to $4.5 \mathrm{~g} / \mathrm{dL}$ ) & 4.2 & & & & 3.9 & \\
\hline ALT (0 to $45 \mathrm{UI} / \mathrm{L})$ & 56 & 35 & 36 & 20 & 16 & 65 \\
\hline AST (0 to $45 \mathrm{UI} / \mathrm{L}$ ) & 66 & 65 & 70 & 34 & 36 & 58 \\
\hline GGT (7 to 49UI/L) & 344 & 197 & 197 & 181 & 266 & 277 \\
\hline ALP (80 to $320 \mathrm{UI} / \mathrm{L}$ ) & 2534 & 1819 & 1671 & 1360 & 1652 & - \\
\hline TB (0.00 to $1.20 \mathrm{mg} / \mathrm{dL})$ & 1.91 & 1.2 & 1.69 & 1.2 & 1.27 & 1.44 \\
\hline DB (0.00 to $0.25 \mathrm{mg} / \mathrm{dL})$ & 1.37 & 0.79 & 1.18 & 0.86 & 0.88 & 1.0 \\
\hline Amylase (30 to 118 ) UI/L & 44 & & & & & 47 \\
\hline Immunoglobuline lgG (650 to $1600 \mathrm{mg} / \mathrm{dL}$ ) & 3360 & & & & & \\
\hline lgG4 (110 to $1570 \mathrm{mg} / \mathrm{dL})$ & 521 & & & & & \\
\hline Azotemia (10 to $50 \mathrm{mg} / \mathrm{dL}$ ) & 22 & & & & 14 & \\
\hline Creatinine $(0.50$ to $1.40 \mathrm{mg} / \mathrm{dL})$ & 0.68 & & & & 0.5 & \\
\hline $\operatorname{ESR}\left(1\right.$ to $\left.251^{\circ} \mathrm{h}\right)$ & 104 & 81 & 120 & 99 & 120 & 120 \\
\hline C-RP (0.0 to $0.5 \mathrm{mg} / \mathrm{dL})$ & 4.8 & 2.8 & 7.7 & 5.4 & 1.6 & \\
\hline CMV-lgG (<20U/mL neg) & 11.4 & & 79 & & & 65 \\
\hline CMV-lgM (<20U/mL neg) & 11.2 & & 69 & & & 43 \\
\hline CMV-Avidity Index $<0.5$ low & & & 0.2 & & & 0.1 \\
\hline Blood CMV-PCR (copies/mL) & & $<253$ & 6189 & & & \\
\hline Urine CMV-PCR (copies/mL) & & & 1431 & & & \\
\hline Appendix CMV-PCR *(copies/mL) & & & & 1210 & & \\
\hline Appendix culture & & & & Positive & & \\
\hline Appendix immunohistochemistry & & & & Positive & & \\
\hline
\end{tabular}

ALP, alkaline phosphatase; ALT, alanine aminotransferase; AST, aspartate aminotransferase; C-RP, C Reactive Protein; DB, direct bilirubin; ESR, erythrocyte sedimentation rate; GGT, gamma-glutamyl transpeptidase; I.N.R, international normalized ratio; PLT, platelets; RBCs, red blood cells; TB, total bilirubin; WBCs, white blood cells. *DNA-CMV was quantified (Q-CMV Real Time, Nanogen Advanced Diagnostics, Torino, Italy) after tissue digestion for 30 minutes at $56^{\circ} \mathrm{C}$ with proteinase $\mathrm{K}$ buffer $500 \mu \mathrm{L}$ (Diatech Laboratories, Jesi, Italy) and DNA extraction with EasyMAG (bioMerieux, Merci L'Etoile, France), following the manufacturers' instructions.

was $0.38 \mathrm{ng} / \mathrm{ml}$. The fever persisted while the upper abdominal pain subsided slightly. Investigations for HIV, Toxoplasma gondii, CMV, measles, parotitis and hepatitis $\mathrm{C}$ virus $(\mathrm{HCV})$ all were negative, while results for varicella zoster virus, human herpes virus, Epstein Barr, rubella, and parvo virus B19 indicated previous infection. CD4 + T lymphocytes were $1055 \mathrm{~mm}^{3}$ (20.3\%) and $\mathrm{CD} 3+\mathrm{T}$ lymphocytes were $3193 \mathrm{~mm}^{3}$ (67\%).
Mycobacterium tuberculosis interferon gamma release assay (QuantiFERON ${ }^{-}-\mathrm{TB}$ Gold, Cellestis Limited, Carnegie, Victoria, Australia) showed negative results. Twelve days after admission, teicoplanin 400mg die, gentamicin $80 \mathrm{mg}$ TID, metronidazole 500mg TID were prescribed, while tigecycline was stopped. Two days later, deoxyribonucleic acid (DNA) Cytomegalovirus (Q-CMV Real Time, Nanogen Advanced Diagnostics, Torino, Italy) 

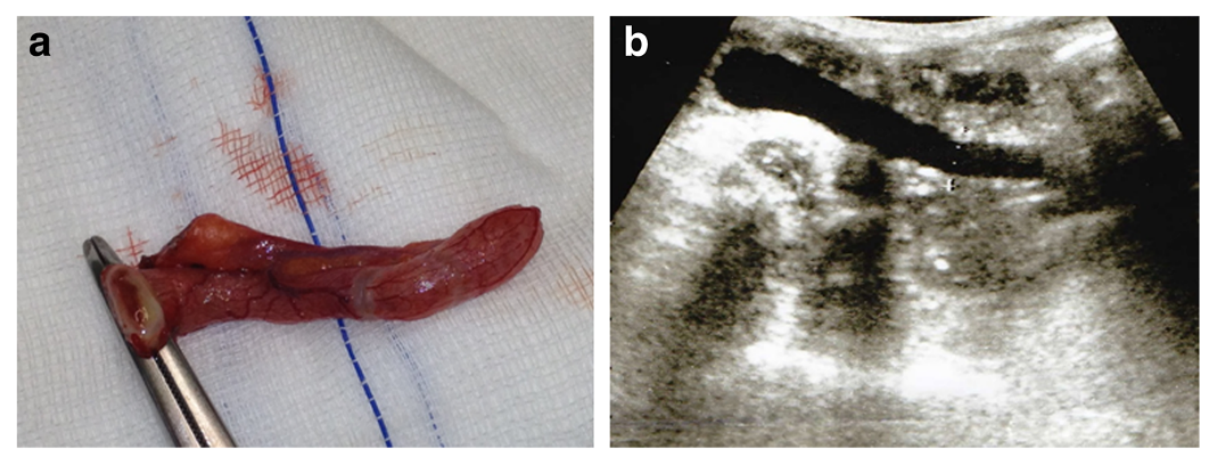

Figure 2 Acute catarrhal appendicitis (a); abdominal ultrasound showing "finger in glove" anechoic image with incompressible lumen (b).

was detected in the blood with $\leq 253$ copies $/ \mathrm{mL}$. Three days later, this value increased to 6189 copies $/ \mathrm{mL}$, while 1431 copies $/ \mathrm{mL}$ were evidenced from a urine sample, the CMV pp65-antigen (Indirect Immunofluorescence, anti-CMV pp-UL83, Argene, France) was also positive, and CMV serology indicated acute CMV infection (Table 1). Our patient's fever rose to $39.2^{\circ} \mathrm{C}$ and his abdominal pain extended to the right lower abdominal quadrant with radiation to the right groin and right testicle. Ultrasound (Figure 2a) suggested acute appendicitis and he underwent surgery (Figure $2 \mathrm{~b}$ ). Histology showed inflammatory infiltrates, including lymphocytes and neutrophils, while histochemistry was positive for CMV early antigens (Monoclonal Mouse Anti-Cytomegalovirus Clone CCH2 + DDG9, Ventana Medical System, Roche, USA) (Figure 3). Real time reaction and shell vial culture of the appendix tissue also were positive. Microbiological investigations for bacteria and fungi showed Peptococcus spp. and Candida albicans. Teicoplanin, gentamicin and metronidazole were administered for a total of 12 days along with intravenous

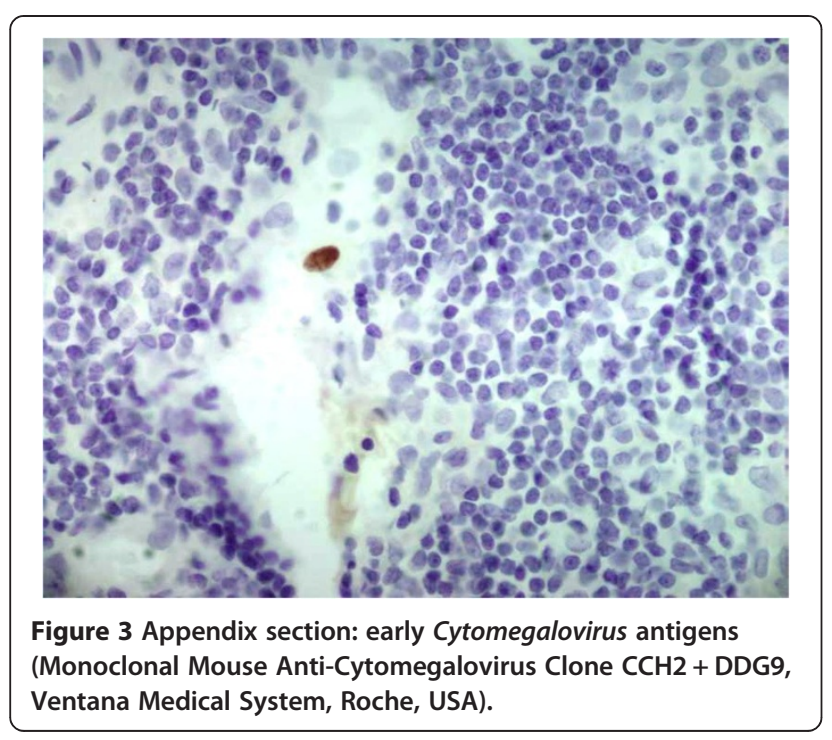

ganciclovir $5 \mathrm{mg} / \mathrm{kg}$ twice for 15 days. After discharge, oral valganciclovir $900 \mathrm{mg}$ BID was prescribed for 10 days. After this, the CMV nucleic acid in the blood and urine was negative while ESR and cholestatic liver test results remained abnormally high (Table 1).

\section{Discussion}

Primary sclerosing cholangitis is a disease of the bile ducts that causes inflammation and subsequent obstruction of the intra-hepatic and extra-hepatic bile ducts. Over time, the inflamed ducts develop scar tissue and this disrupts bile flow [13]. In addition to bile duct disease, 60 to $80 \%$ of patients with PSC have inflammatory bowel disease, typically ulcerative colitis [13]. Patients with PSC-UC may have a different phenotype compared to classic UC. Despite minimal endoscopic activity, these patients have more extensive colon involvement, more active histology inflammation and an increased risk of colorectal cancer $[13,14]$. An inverse prognostic relationship between PSC and UC has also been observed and progressive PSC requiring a liver transplant seems to be associated with UC, that is less symptomatic and less often requires colectomy [13]. Florin et al. investigated for an interaction between appendectomy and PSC in the epidemiology and clinical behavior of PSC-UC, finding no lower rates of appendectomy in PSC patients. However, prior appendectomy appeared to be associated with approximately a five-year delay in the onset of intestinal or hepatic disease [15]. A subgroup of patients with PSC having an overlap syndrome characterized by lymphoplasmacytic infiltrates, rich in IgG4-positive cells, has been identified $[13,16]$. Similar to classic PSC, these patients may have other autoimmune disorders, including autoimmune pancreatitis, autoimmune hepatitis, inflammatory bowel diseases, Sjögren's syndrome, nephritis and retroperitoneal fibrosis $[13,16,17]$. This immunoglobulin overlapping syndrome has been reported to be ameliorated with corticosteroid therapy $[13,16]$. Regarding our case report, the normal value of IgG4 excluded a diagnosis of 
PSC with overlapping IgG4 disease [13,16]. Moreover, the retroperitoneal fibrosis had a mild clinical progressive behavior. For these reasons, our patient was never treated with corticosteriods or immunosuppressive therapy.

CMV has also been implicated as a possible etiology in sclerosing cholangitis-like syndrome in patients with HIV infection [1,18]. CMV infection was not the cause of liver and bile duct disease in our patient. Also, clinical laboratory and endoscopic findings did not indicate CMV colitis [1,2,19]. In fact, typical CMV endoscopic findings were not detected, while CMV antibodies and CMV antigens were positive only 10 days after our patient was admitted.

At admission, our patient presented with right upper abdominal pain, elevated leucocyte and neutrophil counts, increased bilirubin, GGT and ALP levels. Therefore, recurrent bacterial cholangitis was the admitting diagnosis. However, despite an initial improvement with the administration of antimicrobials, his condition worsened due to increased fever and abdominal pain, also involving, at that time, the right lower abdominal quadrant, right groin and testicle. Acute appendicitis was diagnosed based on the clinical and ultrasound findings. Simultaneously, laboratory results indicated acute CMV infection; acute appendicitis due to CMV complicating acute CMV infection was suspected. Anti-CMV treatment was added to antimicrobials and our patient underwent surgery.

In our patient, CMV acute infection and acute CMV appendicitis were diagnosed based on: 1) CMV serology; 2) CMV DNA in the blood; 3) peripheral blood lymphocytosis; 4) the presence of CMV early antigen with immunohistochemistry in the appendix; 5) evidence from the literature that CMV gastrointestinal diseases, including florid appendicitis, can also occur in patients apparently non-immunocompromised [2,3,8-12]. Our patient was HIV negative and was never treated with immunosuppressive drugs; however, it is plausible that the chronic inflammatory state involving the intra-hepatic and common bile ducts and the colon or the primary CMV infection itself induced a temporary moderate lowering of $\mathrm{CD} 4+\mathrm{T}$ lymphocytes causing a change in the immune reactivity favoring CMV organ disease [2,3,20]. The absence of intra-nuclear "owl's eye" in the histology cannot exclude the diagnosis, given that this specific histological finding has a lower sensitivity than immunohistochemistry and molecular diagnostic methods [21].

\section{Conclusions}

CMV should be included among the etiologic agents of acute appendicitis in patients with primary sclerosing cholangitis and ulcerative colitis. Currently, there are no definitive data regarding the frequency of CMV appendicitis and the role of anti-CMV treatment in HIV negative and apparently immunocompetent subjects.

\section{Consent}

Written informed consent was obtained from the patient for publication of this case report and any accompanying images. A copy of the written consent is available for review by the Editor-in-Chief of this journal.

\begin{abstract}
Abbreviations
ALP: Alkaline phosphatase; ALT: Alanine aminotransferase; AST: Aspartate aminotransferase; BID: Two times a day; CMV: Cytomegalovirus; CMV-IgM: CMV immunoglobulin M; CMV-PCR: CMV-polymerase chain reaction; C-RP: C-reactive protein; DB: Direct bilirubin; ESR: Erythrocyte sedimentation rate; GGT: Gamma glutamyl transpeptidase; HCV: Hepatitis C virus; HIV: Human immunodeficiency virus; IgG: Immunoglobulin G; IL-6: Interleukin-6; IL-8: Interleukin-8; I.N.

R: International normalized ratio; IV: Intravenous; kPa: Kilopascal pressure; PLT: Platelets; PSC: Primary sclerosing cholangitis; RBC: Red blood cell; TB: Total bilirubin; TID: Three times a day; UC: Ulcerative colitis; WBC: White blood cell.
\end{abstract}

\section{Competing interests}

The authors declare that they have no competing interests.

\section{Authors' contributions}

PMB, SC, FS and OM cared for our patient, acquired, analyzed and interpreted the patient's data, reviewed the literature, and were the major contributors in writing the manuscript. SC was involved with our patient's care and reviewed the manuscript for important intellectual content. DF, RC, EC and AS carried out microbiological testing and reviewed the manuscript for important intellectual content. PB and AP did histological testing and reviewed the manuscript for important intellectual content. FB reviewed the manuscript and gave the final approval of the version to be published. All authors read and approved the final manuscript.

\section{Acknowledgements}

We would like to thank Professor Tiaziana Lazzarotto and Doctor Liliana Gabrielli of the Virology Laboratory, Operative Unit of Microbiology, St' Orsola-Malpighi, University Hospital, Bologna, Italy for their assistance in the CMV immunohistochemistry and their critical reading of the manuscript. We would also like to extend our thanks to our patient for providing his written consent to present this case report and related images.

\section{Author details}

'Infectious Disease, Department Experimental Medicine and Biochemical Sciences, University of Perugia, 06100 Perugia, Italy. ${ }^{2}$ Gastroenterology, Department of Clinical and Experimental Medicine, University of Perugia, 06100 Perugia, Italy. ${ }^{3}$ Microbiology, Department Experimental Medicine and Biochemical Sciences, University of Perugia, 06100 Perugia, Italy. ${ }^{4}$ Pathology and Diagnostic Cytology, Hospital Santa Maria della Misericordia, 06100 Perugia, Italy. ${ }^{5}$ General Surgery, Department of Surgical Sciences, Hospital Santa Maria della Misericordia, 06100 Perugia, Italy. ${ }^{6}$ Unit of Pathology, St' Orsola Malpighi University Hospital, Bologna, Italy.

Received: 5 August 2013 Accepted: 16 December 2013

Published: 10 March 2014

\section{References}

1. Crumpacker CS, Zhang JL: Cytomegalovirus. In Principles and Practice of Infectious Diseases. Edited by Mandell GL, Bennett JE, Dolin R. Philadelphia, PA: Churchill Livingstone; 2010:1971-1987.

2. Chetty R, Roskell DE: Cytomegalovirus infection in the gastrointestinal tract. J Clin Pathol 1994, 47:968-972

3. Rafailidis PI, Mourtzoukou EG, Varbobitis IC, Falgas ME: Severe Cytomegalovirus infection in apparently immunocompetent patients: a systematic review. Virol J 2008, 5:47-54.

4. Davidson T, Allen-Mersh TG, Gazzard B, Wastell C, Vipond M, Stotter A, Miller RF, Fieldman NR, Slack WW: Emergency laparotomy in patients with AIDS. Br J Surg 1991, 78:924-926.

5. Tucker RM, Swanson S, Wenzel RP: Cytomegalovirus and appendiceal perforation in a patient with acquired immunodeficiency syndrome. South Med J 1989, 82:1056-1057.

6. Barocco AL, Oldfield EC: Gastrointestinal Cytomegalovirus disease in the immunocompromised patient. Curr Gastrenterol Rep 2008, 10:409-416. 
7. Posen A, Renckens I, Sagaert X, Kuypers D: Subacute Cytomegalovirus appendicitis in a renal transplant recipient. Transpl Infect Dis 2012, 15:96-97.

8. Blackman E, Vimadal S, Nash G: Significance of gastrointestinal Cytomegalovirus infection in homosexual males. Am J Gastroenterol 1984, 79:935-940

9. Kanafani ZA, Sharara Al, Shabb NS, Kanj SS: Cytomegalovirus appendicitis following acute Epstain-Barr virus infection in an immunocompetent patient. Scand J Infect Dis 2004, 36:505-506.

10. You DM, Johnson MD: Cytomegalovirus infection and the gastrointestinal tract. Curr Gastroenterol Rep 2012, 14:334-342.

11. Dzabic M, Boström L, Rahbar A: High prevalence of an active Cytomegalovirus infection in the appendix of immunocompetent patients with acute appendicitis. Inflamm Bowel Dis 2008, 14:236-241.

12. Katzoli P, Sakellaris G, Ergazaki M, Charissis G, Spondidos DA, Sourvinos G: Detection of herpes viruses in children with acute appendicitis. J Clin Virol 2009, 44:282-286.

13. Eaton JE, Talwalker JA, Lazaridis K, Gores GJ, Lindor KD: Pathogenesis of primary sclerosing cholagitis and advances in diagnosis and management. Gastroenterol 2013, 145:521-535.

14. Rubin DT, Huo D, Kinnucan JA, Sedrak MS, McCullom NE, Bunnag AP, Raun-Royer EP, Cohen RD, Hanauer SB, Hart J, Turner JR: Inflammation is an independent risk factor for colonic neoplasia in patients with ulcerative colitis: a case-control study. Clin Gastroenterol Hepatol 2013, 11:1601-1608. e4.

15. Florin TH, Pandeya N, Radford-Smith GL: Epidemiology of appendicectomy in primary sclerosing cholangitis and ulcerative colitis: its influence on the clinical behaviour of these diseases. Gut 2004, 53:973-979.

16. Ghazale A, Chari ST, Zhang L, Smyrk TC, Takahashi N, Levy J, Topazian MD, Clain JE, Person RK, Petersen BT, Wege SS, Lindor K, Farnell MB: Immunoglobulin G4-associated cholangitis: clinical profile and response to therapy. Gastroenterol 2008, 134:706-715.

17. Mouzas IA, Azezinis P, Karampekios S, Matrella E, Koulentaki M, Kouroumalis EA: Retroperitoneal fibrosis during the course of ulcerative colitis. A simple coincidence? Dig Liver Dis 2001, 33:587-590.

18. Mehal WZ, Hattersley AT, Chapman RW, Fleming KA: A survey of Cytomegalovirus (CMV) DNA in primary sclerosing cholangitis (PSC) liver tissues using a sensitive polymerase chain reaction (PCR) based assay. J Hepatol 1992, 15:396-399.

19. Criscuoli V, Rizzuto MR, Cottone M: Cytomegalovirus and inflammatory bowel disease: is there a link? World I Gastroenterol 2006, 12:4813-4818.

20. Rahbar A, Bostrom L, Lagersted U, Magnusson I, Sodeberg-Naucler C, Sundqvist VA: Evidence of active Cytomegalovirus infection and increased production of IL- 6 in tissue specimens of patients with inflammatory bowel diseases. Inflamm Bowel Dis 2003, 32:983-986.

21. Lamps LW: Infectious causes of appendicitis. Infect Dis Clin N Am 2010, 24:995-1018.

doi:10.1186/1752-1947-8-92

Cite this article as: Pasticci et al:: Acute appendicitis due to

Cytomegalovirus in an apparently immunocompetent patient: a case report. Journal of Medical Case Reports 2014 8:92.

\section{Submit your next manuscript to BioMed Central and take full advantage of:}

- Convenient online submission

- Thorough peer review

- No space constraints or color figure charges

- Immediate publication on acceptance

- Inclusion in PubMed, CAS, Scopus and Google Scholar

- Research which is freely available for redistribution

Submit your manuscript at www.biomedcentral.com/submit
C Biomed Central 